


\section{EDIFÍCIO RESIDENCIAL: \\ ESTRATÉGIAS \\ ALTERNATIVAS}

10 lugar na categoria Trabalho Final de Graduação na

XVª Premiação do IAB-MG, 2013

WALESKA CAMPOS RABELO

Graduação: Curso de Arquitetura e Urbanismo da PUC Minas,

$2^{\circ}$ semestre de 2013

Orientador: Prof. Antonio Grillo

\section{Endereço para correspondência}

Rua Professor Ziller 191, Minas Brasil

30730-200 Belo Horizonte - MG

E-mail: waleskacamposrabelo@gmail.com 


\section{Contextualização}

A paisagem urbana de Belo Horizonte, em constante transformação, é composta por edifícios de variadas épocas e estilos. As principais características de cada momento determinam a qualidade e a maneira de ocupar o espaço, e são orientadas pelo contexto sócio-econômico no tempo em que foram concebidos.

Atualmente, a demanda na produção da arquitetura, especificamente de moradia, também responde a um contexto sócio -econômico, mas a visão da construção civil exclusivamente como negócio imobiliário tem feito da arquitetura um produto de segundo plano. Além disso, a tradicional concepção espacial desenvolvida sob uma matriz envelhecida de família nuclear é ultrapassada; com a formação de novos padrões de grupos domésticos se faz necessário repensar a configuração dos espaços habitacionais. Nos moldes do mercado, privilegiase o apelo à imagem da sociedade de consumo estampada em argumentos frívolos, como espaços gourmet, fitness, playground, garage band; como agravante, estes são espaços que têm um alto custo de manutenção. Os agentes mais importantes nesse tipo de produção são o empreendedor, o construtor e o vendedor, restando ao arquiteto um papel secundário na cadeia produtiva imobiliária.

Mesmo considerando-se a viabilidade comercial de um produto estandardizado direcionado a um público majoritário, porque produzir apenas para este público? Como produzir um edifício que seja aceito pelo mercado e ao mesmo tempo possua qualidades que o diferencie dos demais, com uma arquitetura adequada ao lugar proposto, levando em consideração os diversos potenciais que o sítio proporciona? E mais, será que uma produção arquitetônica de qualidade, e economicamente rentável, não é capaz de alterar a lógica comercial imobiliária?

Acredito existir uma dificuldade por parte dos profissionais de arquitetura em entender e atender aos anseios do consumidor final e à pretensão econômica imposta. Qualquer produto arquitetônico será mercadologicamente viável se proporcionar os lucros esperados pelo investidor. Porém, é necessário que haja um equilíbrio entre economia e qualidade ofertada. O ideal seria que o arquiteto, como sujeito importante nessa produção, trabalhasse junto a outros agentes, para não somente alcançar um bom projeto de arquitetura, mas índices favoráveis à sua execução.

\section{O tema}

Considerando a problemática levantada, buscou-se um objeto/ ensaio para enfrentar a questão qualidade versus preço, com a proposta de um edifício residencial com diferenciais que potencializem a importância da boa arquitetura e seu papel na cidade. Partido, criatividade na associação da forma e função do programa, racionalização dos componentes estruturantes, modulação, são alguns dos elementos que fazem da proposta a representação do que posteriormente seria perfeitamente viabilizada em canteiro: uma arquitetura viável, econômica e inteligente. Por uma vontade concentrada na expressão cons- 
trutiva e no processo produtivo, o edifício busca ser reflexo de uma premissa que busca diversidade, movimento, flexibilidade e respeito à paisagem urbana. Como consequência, me parece apropriado exteriorizar as diferenças internamente concebidas e, ainda, usá-las como um recurso para promover a diversidade espacial interna das unidades.

\section{O lugar}

O bairro São Pedro está inserido na região centro-sul de Belo Horizonte, possui características demográficas de média/alta densidade e uma vitalidade urbana - social e cultural - significativa para a cidade. Oferece proximidade de importantes corredores viários e boa oferta de comércios e serviços. O terreno, com $20 \times 39 \mathrm{~m}$ e área de $780 \mathrm{~m} 2$, localiza-se na rua São Domingos Prata e apresenta condicionantes gerais favoráveis ao empreendimento: localização, insolação, ventilação, vista para cidade, e declive pouco acentuado. Por se tratar de uma região com uma capacidade de infra-estrutura instalada restrita, seu parâmetro urbanístico, ZA (Zona Adensada), permite o uso de coeficiente variando entre 1.3 e 2.0. Ainda que o bairro venha modificando sua fisionomia como consequência do adensamento urbano, ele mantém uma característica predominantemente residencial.

\section{O projeto}

A proposta busca otimizar índices de área privativa $X$ área comum, investir em amplas aberturas que propiciem vistas, ventilação e luz. Oferece áreas externas privativas, quintais e varandas para todas as unidades. A fragmentação do corpo do edifício é feita em três partes, fazendo com que as unidades 'respirem' em relação ao núcleo de circulação vertical e tenham uma melhor interação com o entorno.

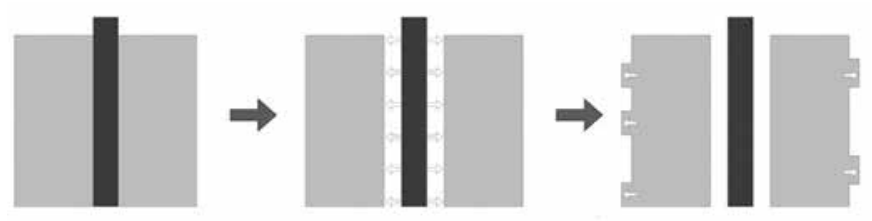

O desenho das unidades seguem os seguintes princípios: linearidade espacial, flexibilidade, nuclearização dos elementos hidráulicos, materiais aparentes, conforto ambiental. Através da análise de possíveis elementos para compor a fachada e promover uma economia construtiva e baixo custo de manutenção, foi escolhido o concreto aparente para o núcleo de circulação vertical, e o "reboco paulista" pintado para as demais fachadas do edifício. Como a fachada oeste coincide com a melhor vista, e por isso dispõe de maiores aberturas, foram adotados brises móveis como recursos para controle de insolação. 


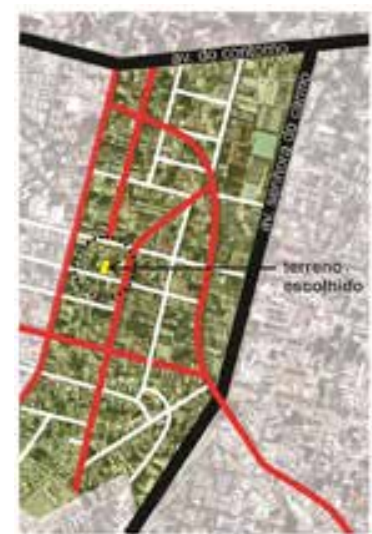

ARTCULACĀO VLARLA - BARRO SĀO PEDRO

Via local

vis soletora

Via anterial
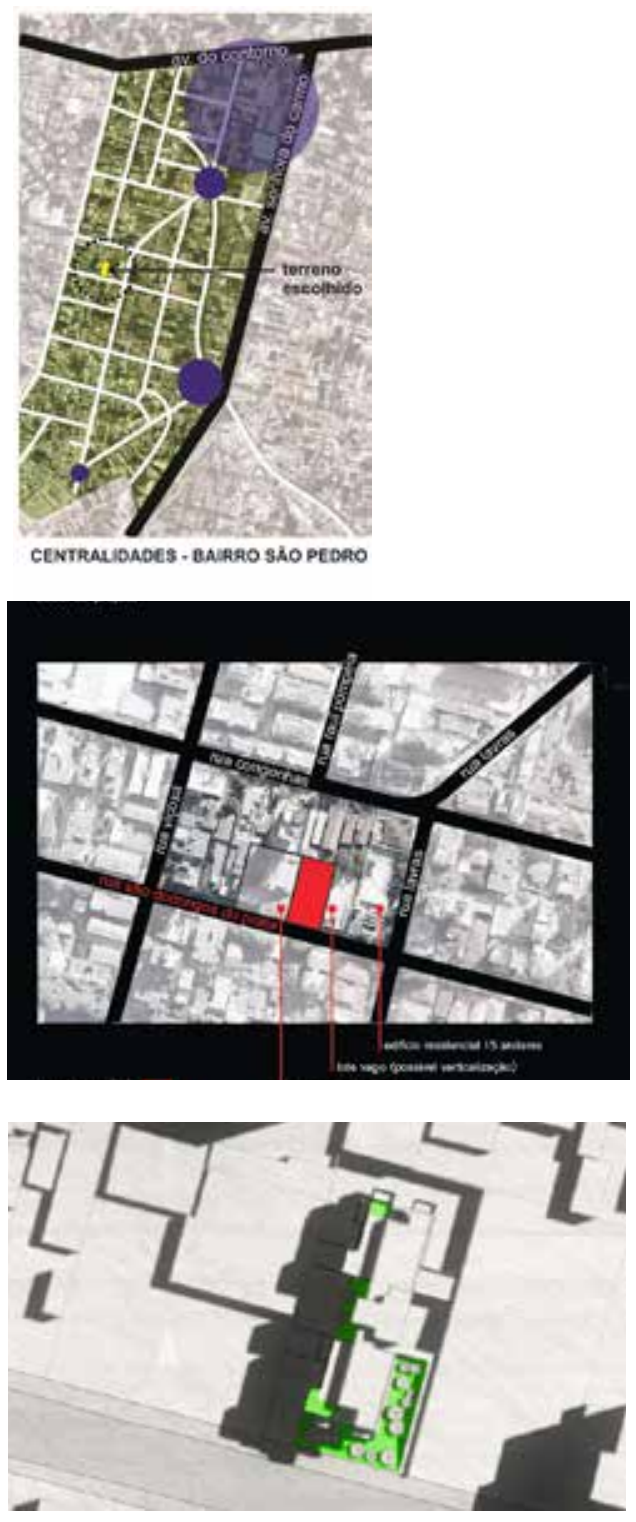

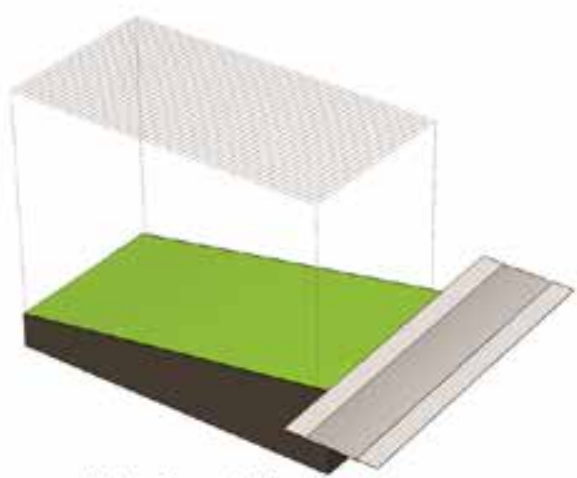

modulação adotada + terreno natural

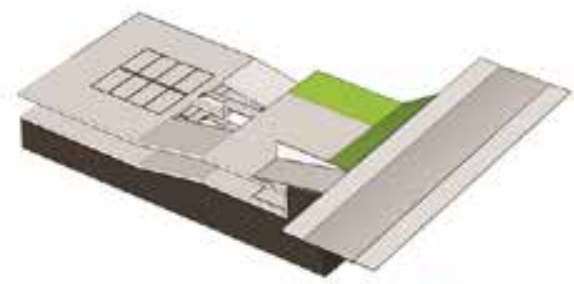

escalonamento do terreno + solução estacionamento

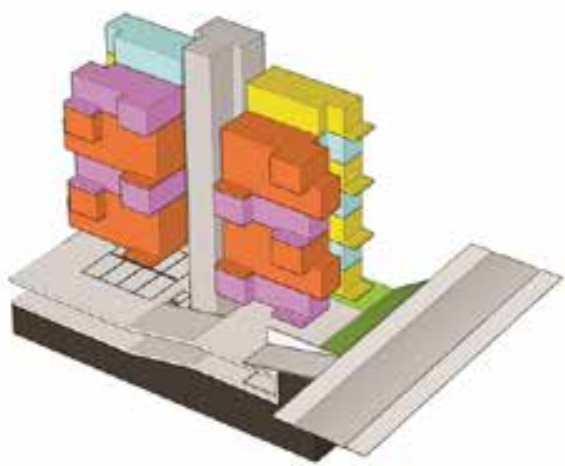

variaçōes das unidades + composiçăo volumétrica

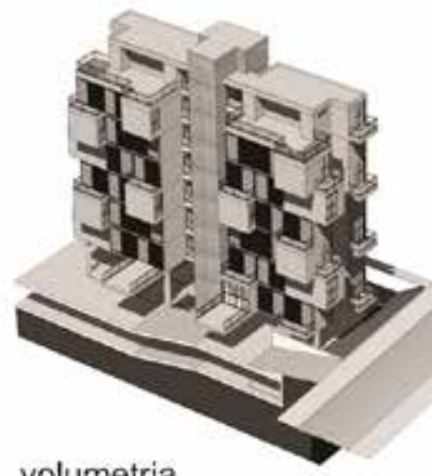

volumetria 

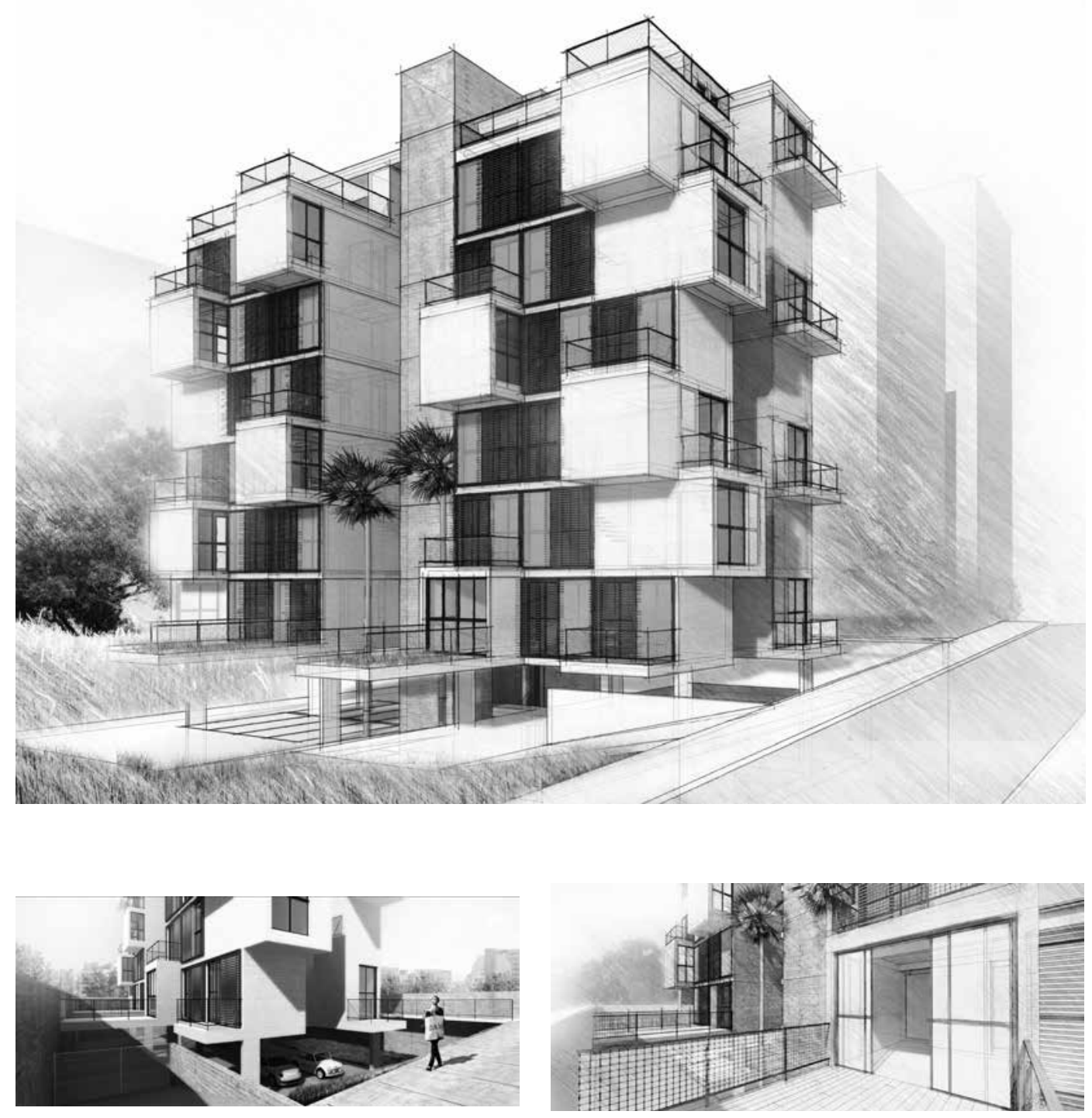


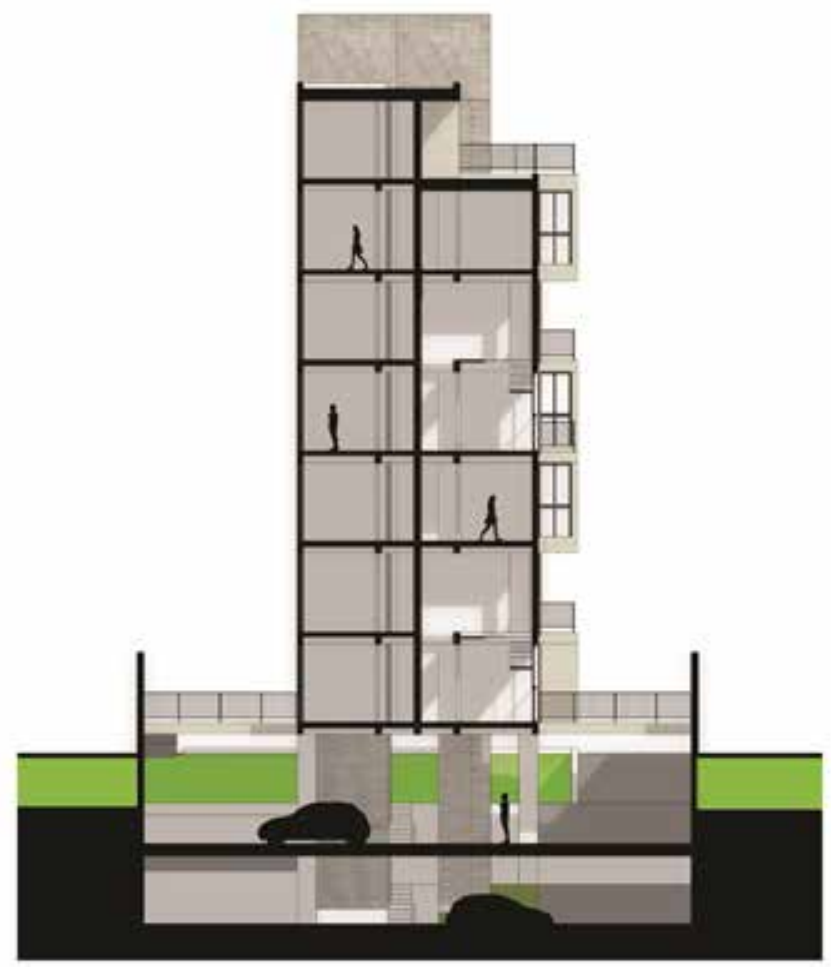

CORTETRANSVERSAL

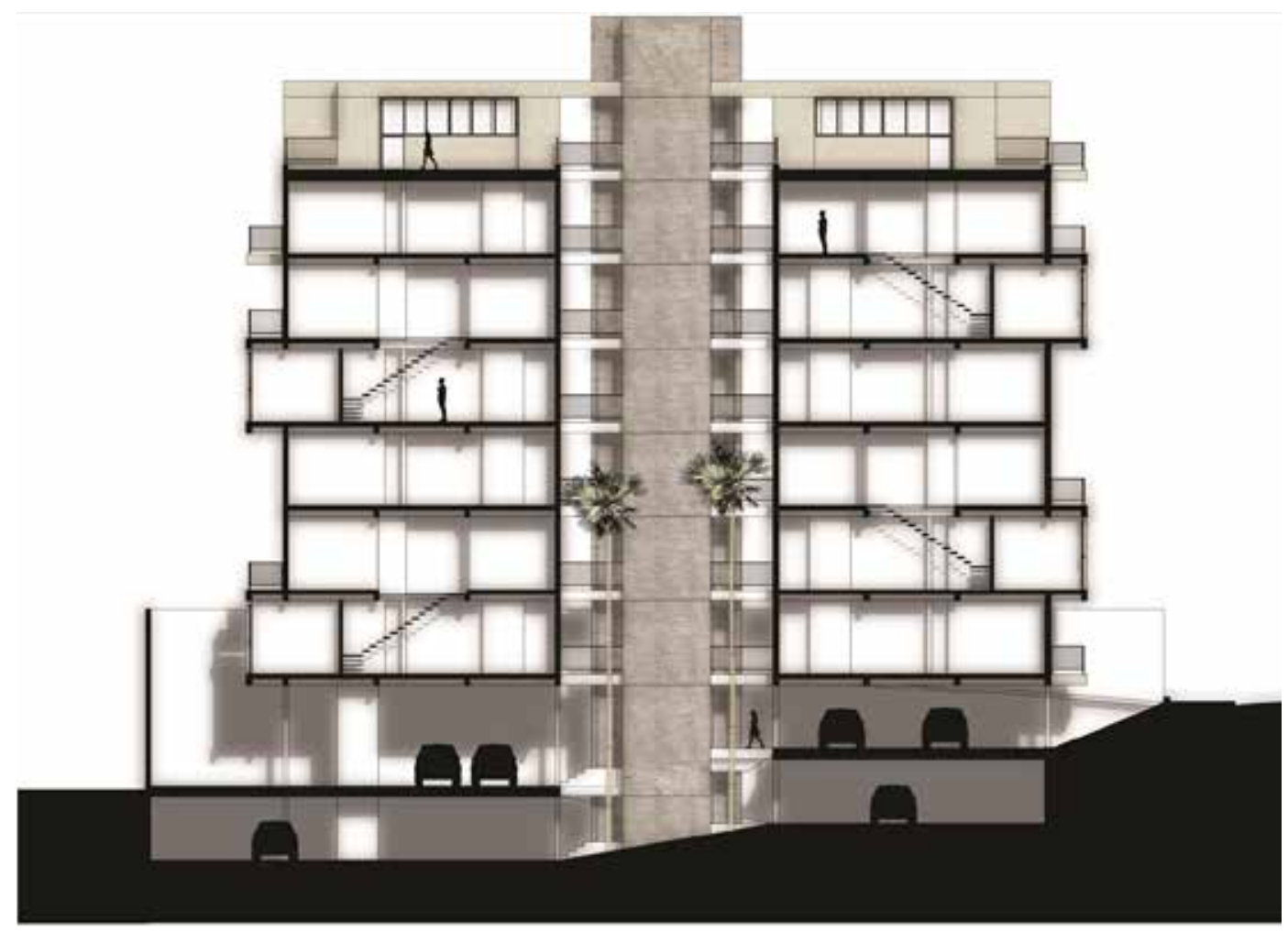

CORTE LONGITUDINAL 


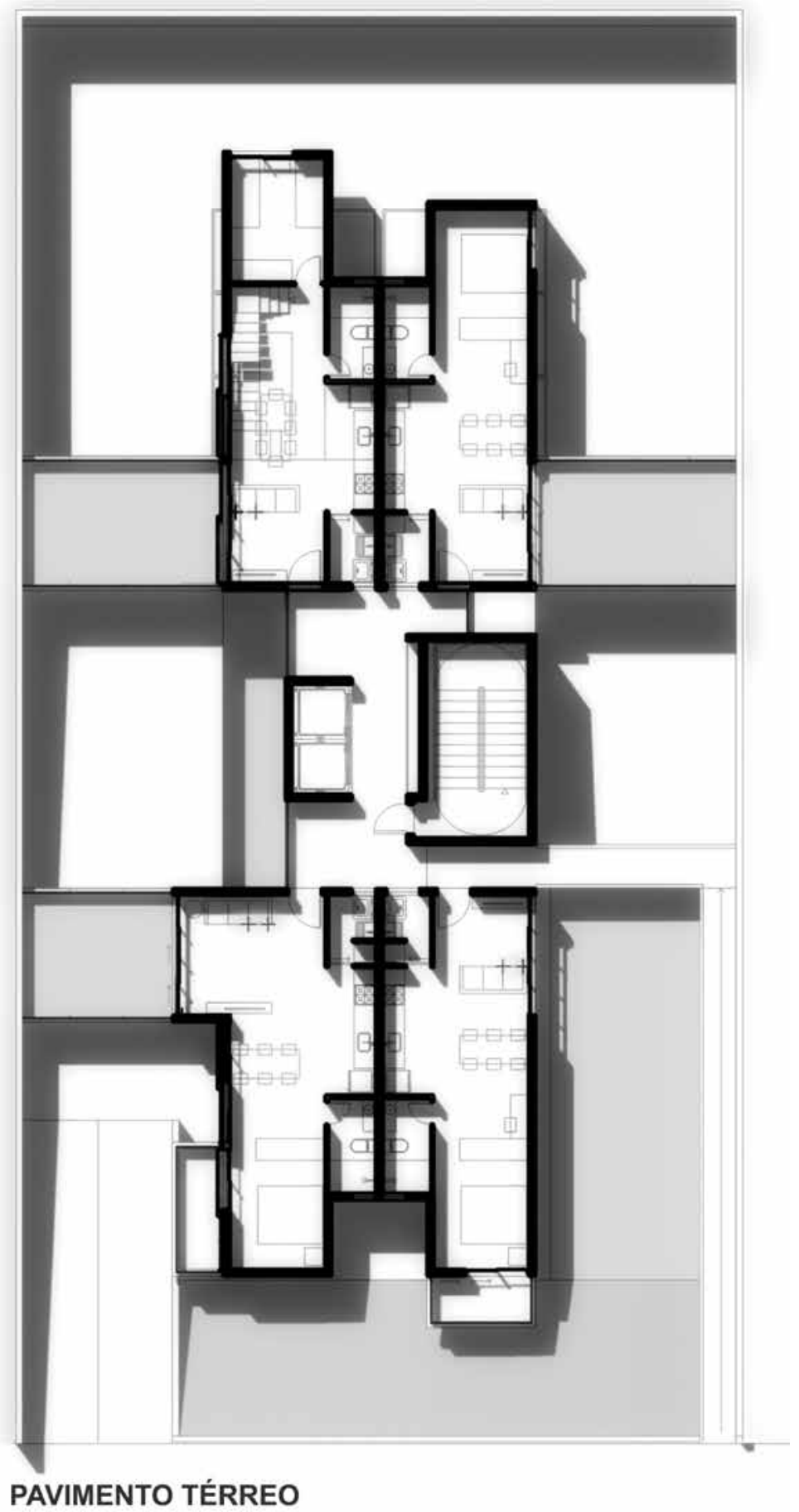

Cadernos de Arquitetura e Urbanismo, v.20, n.27, $2^{0}$ sem. 2013 


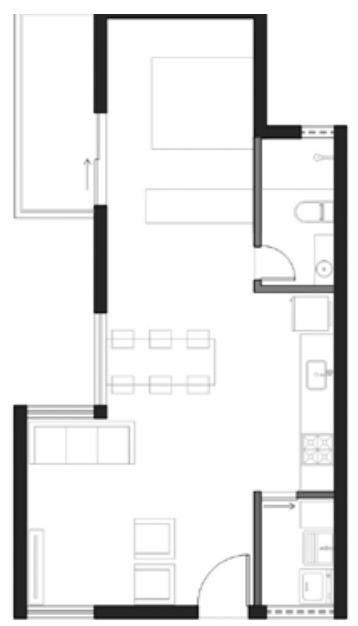

Unidade $01 \mathrm{Q}$ com varanda - 42m2

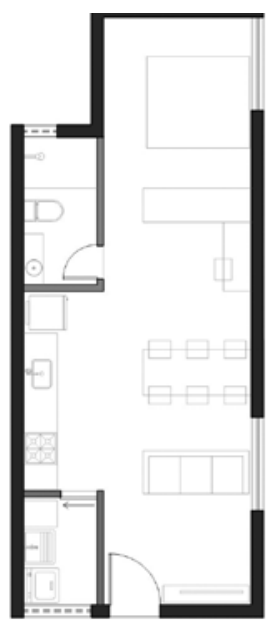

Unidade 01Q $40 \mathrm{~m} 2$

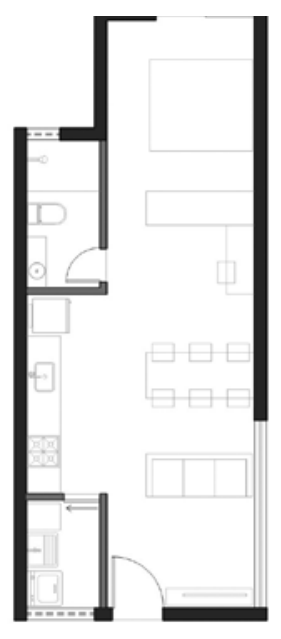

Unidade $01 \mathrm{Q}$ com varanda - $40 \mathrm{~m} 2$

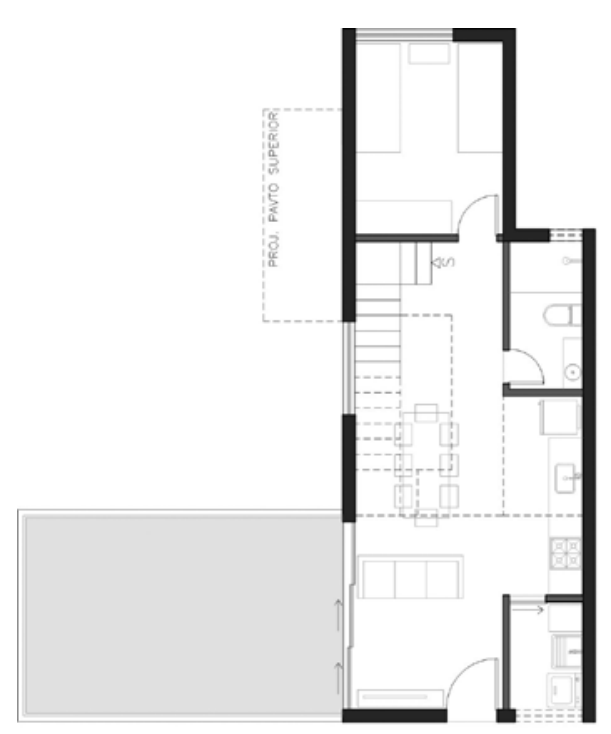

Planta térreo

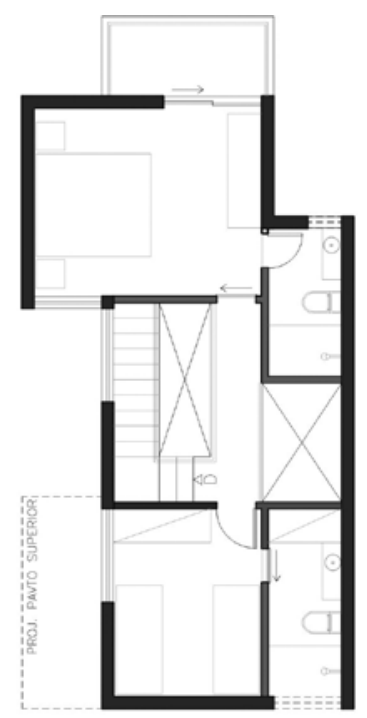

Planta 2o. pav.

Unidade duplex com terraço - 3Q - 80 m2 

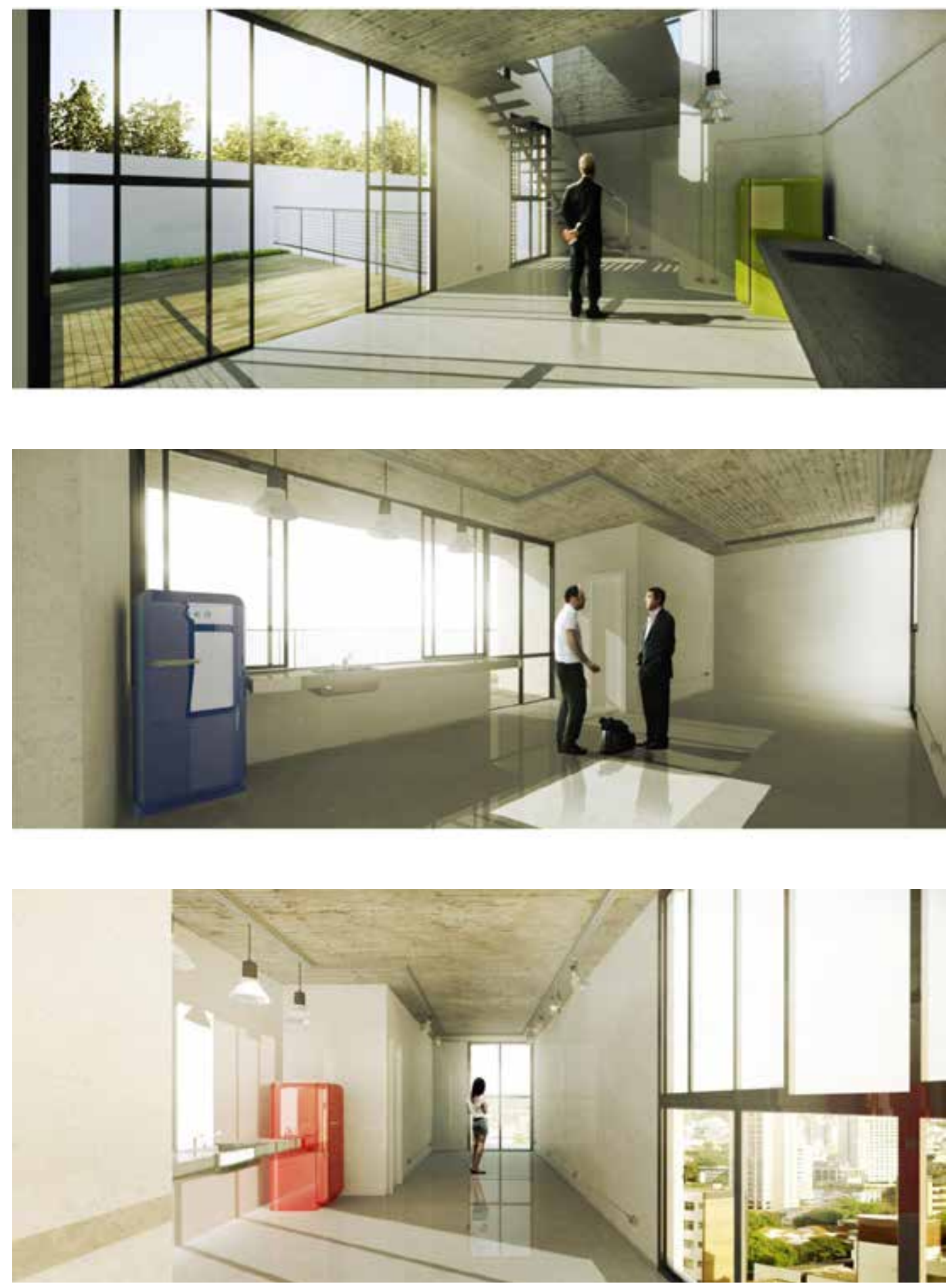

Cadernos de Arquitetura e Urbanismo, v.20, n.27, 2" sem. 2013 


\begin{tabular}{|l|c|}
\hline Componentes obra & $\%$ \\
\hline Instaços provisórias & 2,60 \\
Fundaçōes & 5,00 \\
\hline Alvenarias & 8,00 \\
\hline Estrulura resistente & 19,00 \\
\hline Telhado & 2,50 \\
Instalaços elétrica e telefónica & 7,10 \\
\hline Instalacóes sanitária e de gás & 8,40 \\
\hline Pisos & 6,84 \\
Aparelhos sanitários & 4,38 \\
\hline Aberturas & 8,55 \\
\hline Revestimentos internos & 9,50 \\
\hline Revestimentos externos & 6,36 \\
Pintura & 5,48 \\
Vidros & 1,42 \\
Acabamento e limpeza da obra & 1,42 \\
Elevador & 3,45 \\
\hline
\end{tabular}

\begin{tabular}{|c|c|c|}
\hline Classificação do elemento & Composição & Participação (\%) \\
\hline $\begin{array}{l}\text { Elementos que formam } \\
\text { os planos horizontais }\end{array}$ & $\begin{array}{l}\text { Parte horizontal da estrutura } \\
\text { e das fundaposes, telhado, } \\
\text { pisos e parte horizontal dos } \\
\text { revestimentos e da pintura. }\end{array}$ & 26,79 \\
\hline $\begin{array}{l}\text { Elemenos que formam } \\
\text { cs planot vorticais: }\end{array}$ & 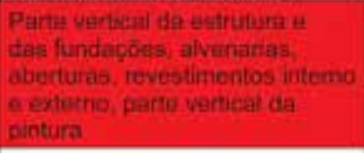 & 44,84 \\
\hline Instalaçoes & $\begin{array}{l}\text { Elétrica, telefonica, hidráulica, } \\
\text { gás, louças e metais e elevador }\end{array}$ & 24.33 \\
\hline $\begin{array}{l}\text { Instalaçoes provisórias, } \\
\text { limpeza da obra e outros } \\
\text { trabalhos nåo considerados }\end{array}$ & - & 4,02 \\
\hline
\end{tabular}

\section{COMPARATIVO INDICES (COMPACIDADE E ÁREA PRIVATIVA)}

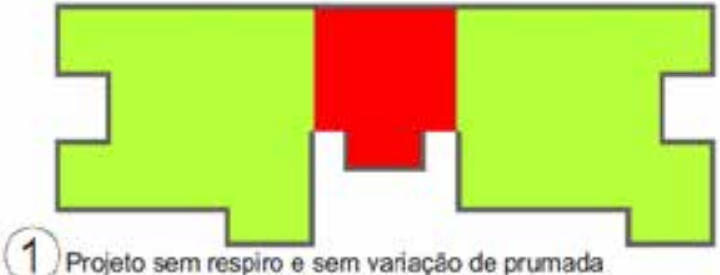

1. Projeto sem respiro e sem variaçăo de prumada

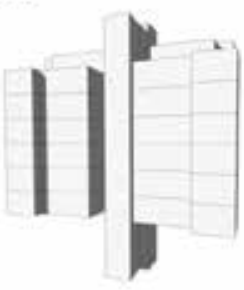

IC: $=$ PCPPX 100

IC $=52,51 / 94 \times 100$

IC $=55,86$

AETIAPT

$219.54 / 183.48=$

1,19

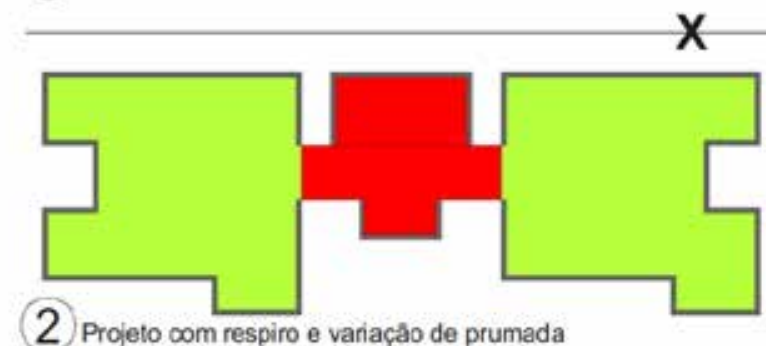

Conchusăo:

- mesma quantidade de balanços

- mesma quansidade de planos verticaís por balanço

- diferenca de menos de 5 pts no indice de compacidade entre as duas tipologias.

-poçuena diferença na roloçăo entre área total $x$ direa privativa

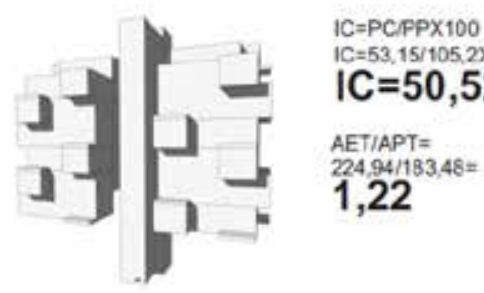

INDICE DE COMPACDADE

ICPPCPPX100:

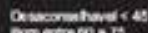

andise

AREA PRIVATIVA TOTAL X AREA EDIFICADA TOTAL

AखTIPT:

Rathina $<130$ 


\section{COMPARATIVO COMPONENTES ESTRUTURAIS $\mathrm{m} 2$ ENSAIO PARA UNIDADE SIMPLEX}
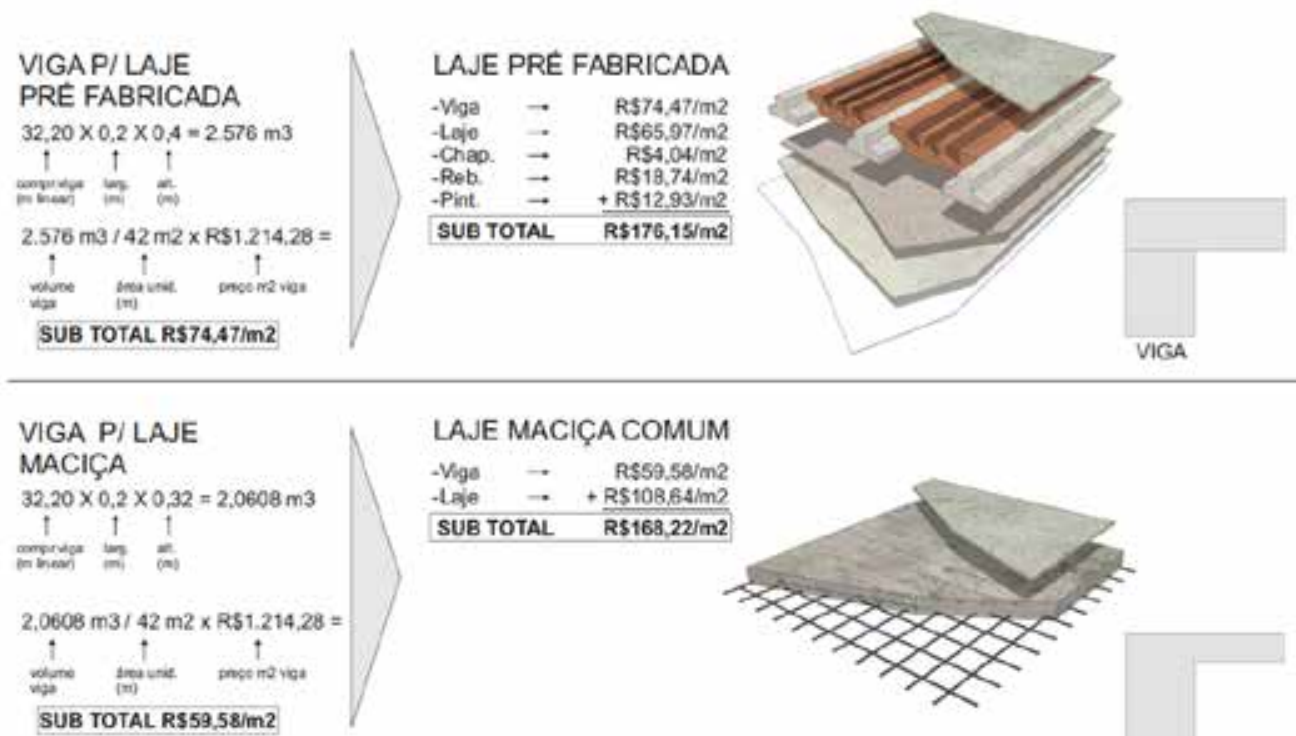

\section{LAJE MACIÇA COMUM}

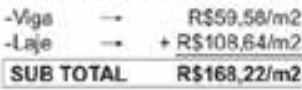

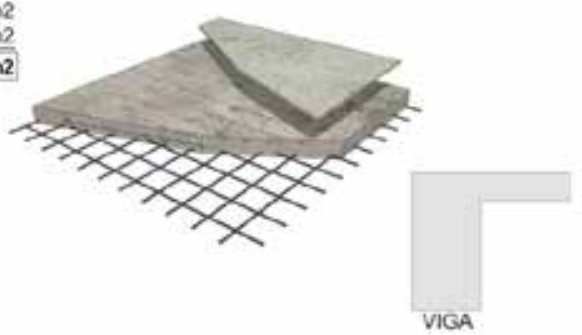

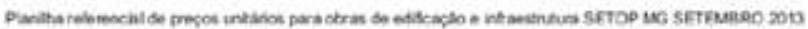

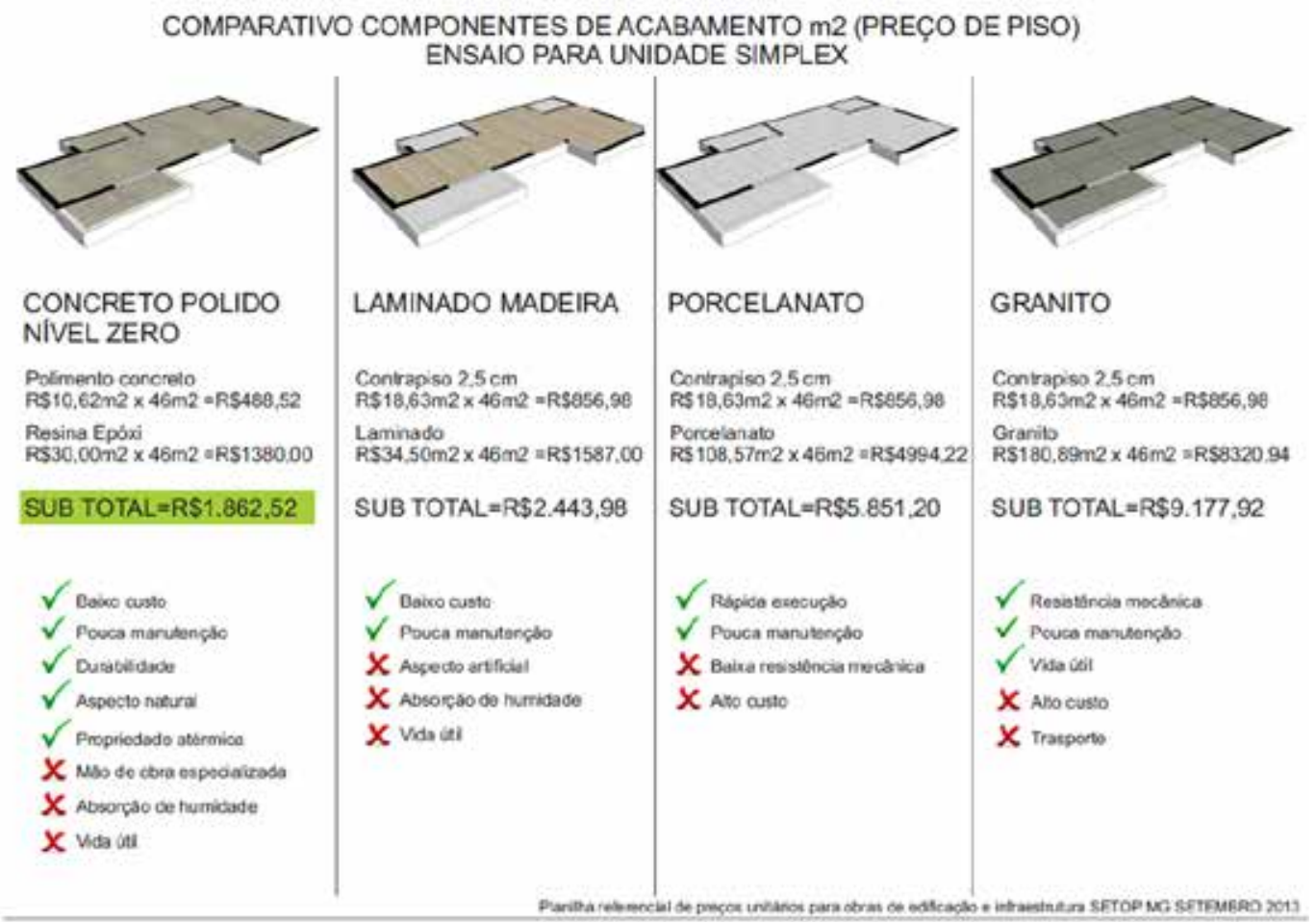




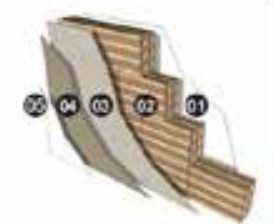

(9) PINTURAACRILICA R\$10,26m2

(1) Roboco intemo com gessoupin bint acrilica R\$26,75m2

(2) Bloco ceramico $20 \mathrm{~cm}$ R\$37,45m2

(19) Chaplsco R.5.,04m2

(3) Reboco RS4.04m2

Sub total R\$98,23

$\checkmark$ Bavo asio

$\checkmark$ Rapidez de enocupto

$\checkmark$ Faclidade na menutenclo

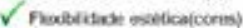

$X$ Manitancaso peribdica

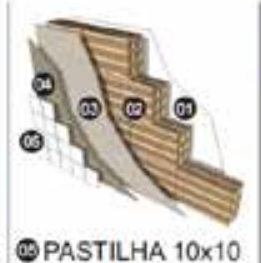
R $\$ 57,83 \mathrm{~m} 2$

(19) Roboco intemo com cessotpintera acrilca $\mathrm{k} 526,75 \mathrm{~m} 2$

(12) Bloce cerdmico $20 \mathrm{~cm}$ R:337,45m?

(19) Chapisco R.54,04me

(1) Angamassa (incluido)

Sub total R\$123,33

$\checkmark$ Medio Custo

$\checkmark$ Povea manieencas

$X$ Tompo de insteloçbo

$X$ Estobsa

$X$ interitisdade esticecs

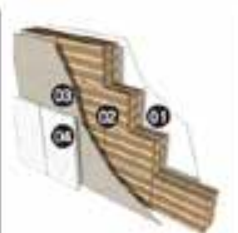

OMARMORE R5180.63n:2

(1) Roboco inkerno com gassootcintura incrives $12 \$ 26,75 m 2$

(1) Eloco corbmico $20 \mathrm{~cm}$ R537,45m2

(1) Chapesco RS4 04me

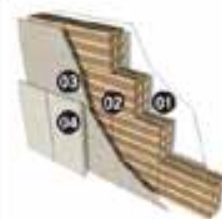

@GRANITO $\mathrm{RS} 177,85 \mathrm{~m} 2$

(9) Raboco interno com gessorpinlura acrilicr R\$\$26, $75 m 2$

(1) Bloco certmico 200m R337,45m?

(2) Chapision

R5. $4.04 \mathrm{~m} 2$

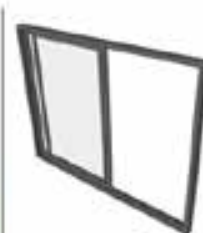

ESQUADRIA

ALUMINIO

+ inarsporte e instataçă

Sub total R\$265,86

Sub total R\$263,08

Sub total R $\$ 490,00$

$\checkmark$ Bom acotamerto

$\checkmark$ Pouce manutencaso

$X$ Torpo de inatacplo

$X$ instracalo especialicada

$X$ infeniolidese estetica

$X$ Cueto ebrivado

$X$ Desenata (vida ver)

$X$ Peso propebo

\begin{tabular}{|c|c|}
\hline$\checkmark$ Bcen acabarnento & $\checkmark$ Bom \\
\hline$\checkmark$ Povca mantercao & $\checkmark$ Pouca mantongas \\
\hline$X$ Temos de instaloglo & $\checkmark$ Rapides bo execustos \\
\hline$X$ insialagiso enpecialuede & $X$ instelacks especistivada \\
\hline$X$ mercelidaso ectitica & $X$ Cusb elevodo \\
\hline$X$ Cusle eivrabs & $X$ Tranmedncia kermica \\
\hline
\end{tabular}

$X$ Pesoproprio

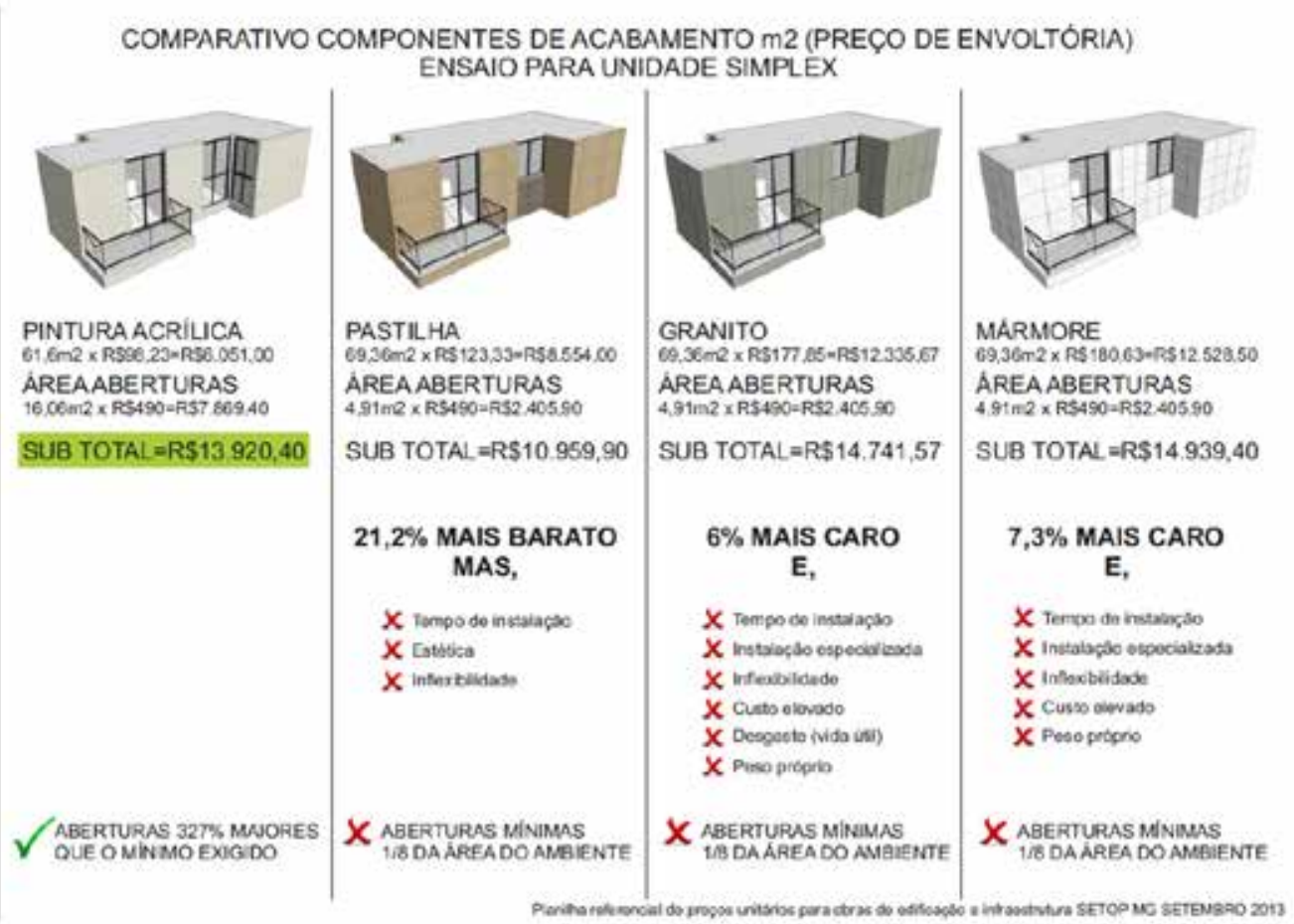

Cadernos de Arquitetura e Urbanismo, v.20, n.27, 2" sem. 2013 
COMPARATIVO DE CUSTO FINAL

CUSTO POR UNIDADE SIMPLEX

\begin{tabular}{|l|l|r|}
\hline PADRÃO A \\
\hline 1. LAJE / FORRO & LAJE PRÉ FABRICADA REBOCADA & $\mathrm{R} \$ 8.102,90$ \\
2. PISO ÁREAS SECAS & PORCELANATO & $\mathrm{R} \$ 5.851,20$ \\
3. PISO ÁREAS MOLHADAS & GRANITO & $\mathrm{R} \$ 641,52$ \\
4. REVESTIMENTO PAREDES EXTERNAS & MÁRMORE & $\mathrm{R} \$ 12.528,50$ \\
5. ESQUADRIAS & ALUMÍNIO -TAMANHO PADRÃO & $\mathrm{R} \$ 2.405,90$ \\
\hline
\end{tabular}

\section{PADRÃO B}

1. LAJE / FORRO

2. PISO ÁREAS SECAS

3. PISO ÁREAS MOLHADAS

4. REVESTIMENTO PAREDES EXTERNAS

5. ESOUADRIAS

LAJE PRÉ FABRICADA REBOCADA
LAMINADO DE MADEIRA
PORCELANATO
PASTILHAS
ALUMÍNIO - TAMANHO PADRÃO

$\mathrm{R} \$ 8.102,90$

$R \$ 2.443,98$

$\mathrm{R} \$ 410,70$

$\mathrm{R} \$ 8.554,00$

$R \$ 2.405,90$

R\$ 21.917,48

\begin{tabular}{|c|c|c|}
\hline \multicolumn{3}{|l|}{ PADRÃO ADOTADO } \\
\hline 1. LAJE / FORRO & LAJE MACIÇA / CONCRETO APARENTE & $\mathrm{R} \$ 7.738,12$ \\
\hline 2. PISO ÁREAS SECAS & CONCRETO POLIDO “NÍVEL ZERO” & $\mathrm{R} \$ 1.725,92$ \\
\hline 3. PISO ÁREAS MOLHADAS & CONCRETO POLIDO “NÍVEL ZERO" & $R \$ 136,60$ \\
\hline 4. REVESTIMENTO PAREDES EXTERNAS & REBOCO PINTADO & $\mathrm{R} \$ 6,051,00$ \\
\hline 5. ESQUADRIAS & ALUMÍNIO - ABERTURAS MAIORES & $\mathrm{R} \$ 7.869,4$ \\
\hline
\end{tabular}

R\$ 23.521,04

\section{CONCLUSÃO}

O padrão adotado, mesmo com aberturas em fachadas com área $327 \%$ maior que o mínimo exigido, mas com opções de materiais de acabamento vinculadas a soluções estruturais-construtivas que conciliam economia e apelo estético, resultou em uma variação inexpressiva no custo final da unidade. 